\title{
Factors of Low Birth Weight Risk in the Department of Gynecology-Obstetrics of the Ignace Deen National University Teaching Hospital in Conakry, Guinea
}

\author{
Abdourahamane Diallo1 ${ }^{*}$, Ibrahima Sory Baldé1, Ibrahima Sory Diallo², Mamadou Hady Diallo3, \\ Mamadou Cellou Diallo1, Elhadj Mamoudou Bah ${ }^{3}$, Ibrahima Koussy Bah', Telly Sy', \\ Mathias Roth-Kleiner4, Mamadou Pathé Diallo² \\ ${ }^{1}$ Obstetrics and Gynecology Department of the Ignace Deen National University Teaching Hospital, Conakry, Guinea \\ ${ }^{2}$ Institute of Nutrition and Child Health (INCH), Donka, Guinea \\ ${ }^{3}$ Obstetrics and Gynecology Department of Donka National University Teaching Hospital, Conakry, Guinea \\ ${ }^{4}$ Department Women-Mother-Child, University Hospital and University of Lausanne, Lausanne, Switzerland \\ Email: *adiallo69gn@yahoo.fr
}

How to cite this paper: Diallo, A., Baldé, I.S., Diallo, I.S., Diallo, M.H., Diallo, M.C., Bah, E.M., Bah, I.K., Sy, T., Roth-Kleiner, M. and Diallo, M.P. (2019) Factors of Low Birth Weight Risk in the Department of Gynecology-Obstetrics of the Ignace Deen National University Teaching Hospital in Conakry, Guinea. Open Journal of Obstetrics and Gynecology, 9, 251-259. https://doi.org/10.4236/ojog.2019.92026

Received: January 17, 2019

Accepted: February 22, 2019

Published: February 25, 2019

Copyright $\odot 2019$ by author(s) and Scientific Research Publishing Inc. This work is licensed under the Creative Commons Attribution International License (CC BY 4.0).

http://creativecommons.org/licenses/by/4.0/ CC) (i) Open Access

\begin{abstract}
Introduction: The underweight at birth is recognized as a major cause of morbidity and mortality in childhood. Objective: To identify maternal and obstetric sociodemographic factors associated with low birth weight. Patients and Methods: This is a retrospective study of analytical type that examined the records of women who gave birth in the Obstetrics and Gynecology department of Ignace Deen National University Teaching Hospital from $1^{\text {st }}$ December 2016 to $30^{\text {th }}$ April 2017. The analysis was made with the $\mathrm{R}$ version 3.3.1 software. We did a univariate and multivariate analysis. Outcomes: Out of the 1633 live births of single pregnancies that occurred during the study period, 109 children were born with a low weight $(<2500 \mathrm{~g})$ corresponding to a rate of $6.7 \%$. In univariate analysis, we found a significant association between low birth weight and maternal single status $(\mathrm{p}=0.019)$, maternal weight less than $60 \mathrm{~kg}(\mathrm{p}=0.038)$, primary parity $(\mathrm{p}=0.018)$, maternal history of abortion $(\mathrm{p}=0.001)$, history of preterm birth $(\mathrm{p}<0.001)$, arterial hypertension ( $\mathrm{p}<0.001)$, anemia $(\mathrm{p}<0.001)$ and malaria $(\mathrm{p}<0.001)$. In multivariate analysis, the variables associated with low birth weight were: history of preterm delivery with OR of 8.5 [1.8 - 40.1], history of abortion $(\mathrm{OR}=4.4$ [1.4 - 13.9]), malaria $(\mathrm{OR}=23.8[6.1-92.5])$, anemia $(\mathrm{OR}=11.8[3.7-38.2])$ and high blood pressure $(\mathrm{OR}=5.4[1.6-17.9])$. Conclusion: The decrease in frequency of low birth weight in Guinea will be done by improving the quality of prenatal care with an emphasis on screening, prevention and treatment
\end{abstract}


of malaria, anemia and high blood pressure during pregnancy, prevention of abortion and premature birth.

\section{Keywords}

Risk Factors, Low Birth Weight, Ignace Deen, Newborn to Term

\section{Introduction}

Low birth weight is defined by the World Health Organization (WHO) as a birth weight at term less than $2500 \mathrm{~g}$ [1]. The underweight at birth is recognized as a major cause of morbidity and mortality in infancy [2] [3]. It can affect the health of the child's growth, development and learning ability [3]. The newborns of low birth weight have an increased risk of death before the age of one year [4]. The risks of morbidity are both prenatal (anoxic-ischemia) and postnatal (hypothermia and hypoglycemia) [2]. These children have a higher risk of minor cognitive deficits, symptoms of hyperactivity, delayed neurodevelopment at 5 years and school problems at 8 years. They are more likely to develop in adulthood cardiovascular disease, high blood pressure, carbohydrate intolerance, diabetes, dyslipidemia and obesity [5]. They are at risk of death two to four times higher than normal weight children [2] [6].

In Guinea, the incidence of low birth weight varies from one administrative area to another. Urban regions of Labé and Conakry have the highest rate with $10 \%$ and $11 \%$ respectively of low birth weight corresponding to one newborn over 10 [3] [7].

The high incidence of low birth weight in Conakry, its negative impact on the health of children and lack of previous research on the subject in the service motivated the realization of this study aimed at identifying maternal sociodemographic and obstetric factors associated with low birth weight.

\section{Material and Method}

This is a retrospective study of analytical type that covered the records of women who gave birth in Obstetrics and Gynecology department of the Ignace Deen National University Teaching (CHU) of Conakry between $1^{\text {st }}$ December 2016 and $30^{\text {th }}$ April, 2017 corresponding to 5 months.

The records of all women who gave birth in this department during this period were included. Incomplete applications and those of the women who gave birth to a stillborn, premature, or malformed newborn infant, twins or triplets were excluded. All the women were assigned to one of the following two groups:

Group 1: composed of women who delivered to term a living infant whose birth weight was less than $2500 \mathrm{~g}$;

Group 2: composed of mothers whose living newborns to term had a birth weight greater than or equal to $2500 \mathrm{~g}$. 
In a case of birth weight $<2500 \mathrm{~g}$, two cases of birth weight $\geq 2500 \mathrm{~g}$ were randomly recruited for comparison. As for the 60 cases of low birth weight, we recruited 120 cases of birth weight $\geq 2500 \mathrm{~g}$ and after increase of $8.5 \%$ we got 130 cases.

The following parameters were compared in both groups,

1) Maternal socio-demographic data: age and weight at birth, educational level, marital status.

2) Obstetric data: parity, history of abortion, premature delivery and antenatal care.

3) Maternal conditions diagnosed during pregnancy: malaria, anemia and high blood pressure.

All data were collected using a pre-survey form based on the objectives of the study. The parameters were analyzed using the $\mathrm{R}$ software version 3.3.1. Initially, an unvaried analysis was performed. To compare the different proportions when all theoretical numbers are greater than 5 , the Pearson $\mathrm{Chi}^{2}$ test was used. When at least one of the theoretical numbers is less than 5 but greater than 2.5, the corrected $\mathrm{Khi}^{2}$ Yates was applied and when at least one of the theoretical numbers is less than 2.5, the exact Fisher test was used.

Then, a multivariate analysis was determined by logistic regression as a variable to explain the low birth weight is a dichotomous categorical variable as explanatory variables and parameters significantly associated with low birth weight. For the selection of these variables to be introduced in the regression model, the process of stepping down has been applied. The results are given in p-value, crude odds ratio (ORb) and adjusted (ORa) and 95\% confidence intervals for each explanatory variable. The association was considered significant when $\mathrm{p}$ was less than $5 \%$ or if the confidence interval of OR b and ORa excludes the value 1 .

\section{Results}

Out of the 1633 term live births in single pregnancies that occurred during the study period, 109 children were born with low birth weight $(<2500 \mathrm{~g})$, corresponding to a rate of $6.7 \%$. But 49 files were incomplete and do not have to be considered. So 60 cases were assigned to group $1(\mathrm{PN}<2500 \mathrm{~g})$ and 130 cases in group 2 (PN $\geq 2500 \mathrm{~g}$ ) (Table 1$)$.

A significant association between low birth weight and the following factors were found: the unmarried status of the mother $(\mathrm{p}=0.019)$, which increases the risk of low birth weight by 2 times (OR $=2.1$ [1.1 - 3.9]) and maternal weight < $60 \mathrm{~kg}(\mathrm{p}=0.038)$ with an increased risk of $50 \%(\mathrm{OR}=1.5[1.2-2.0])$ (Table 2).

A significant association between low birth weight and the following factors was found: the parity $<4(\mathrm{p}=0.018)$ with a risk of low birth weight nearly 3 times greater $(\mathrm{OR}=2.5[1.2-4.9])$, the antecedent abortion $(\mathrm{p}=0.001)$ which multiplies by 3 the risk of low birth weight $(\mathrm{OR}=2.7$ [1.5 - 5.1]) and the antecedent of preterm delivery $(\mathrm{p}<0.001)$, which increases the risk to almost 5 times $(\mathrm{OR}=4.6[2.0-10.2])($ Table 3$)$. 
A highly significant association with maternal conditions during pregnancy was found: high blood pressure $(\mathrm{p}<0.001)$, anemia $(\mathrm{p}<0.001)$ and malaria $(\mathrm{p}<$ 0.001). The risk of low birth weight is multiplied by 6 on the occurrence of hypertension during pregnancy $(\mathrm{OR}=5.6$ [2.9 - 10.9]), with 14 cases of malaria (OR 14.3 [6.0 - 34.0]) and 18 in case of anemia $(\mathrm{OR}=18.3$ [8.5 - 39.4]) (Table 4).

Table 1. A woman has given birth to a newborn under $2500 \mathrm{~g}$ as compared to a woman who gave birth to a newborn of $2500 \mathrm{~g}$ or more according to their sociodemographic characteristics.

\begin{tabular}{|c|c|c|c|c|c|c|c|c|}
\hline \multirow{3}{*}{$\begin{array}{c}\text { Maternal } \\
\text { socio-demographic } \\
\text { characteristics }\end{array}$} & & \multicolumn{4}{|c|}{ Birth weight } & \multirow{3}{*}{ p-value } & \multirow{3}{*}{$\begin{array}{c}\text { OR } \\
\text { gross }\end{array}$} & \multirow{3}{*}{$\begin{array}{c}\text { IC } \\
(95 \%)\end{array}$} \\
\hline & & \multicolumn{2}{|c|}{$<2500 \mathrm{~g}$} & \multicolumn{2}{|c|}{$\geq 2500 \mathrm{~g}$} & & & \\
\hline & & $\mathrm{n}=60$ & $\%$ & $\mathrm{n}=130$ & $\%$ & & & \\
\hline \multicolumn{9}{|l|}{ Married mothers } \\
\hline & Yes & 29 & 25.2 & 86 & 74.8 & \multirow{2}{*}{0.019} & \multirow{2}{*}{2.1} & \multirow{2}{*}{ [1.1 - 3.9] } \\
\hline & No & 31 & 41.3 & 44 & 58.7 & & & \\
\hline \multicolumn{9}{|l|}{ Educated mothers } \\
\hline & Yes & 49 & 29.9 & 115 & 70.1 & \multirow{2}{*}{0.205} & \multirow{2}{*}{0.6} & \multirow{2}{*}[0.2-1.4]{} \\
\hline & No & 11 & 42.3 & 15 & 57.7 & & & \\
\hline \multicolumn{9}{|l|}{ Maternal age (years) } \\
\hline & $<35$ & 60 & 100 & 125 & 96.2 & \multirow{2}{*}{0.125} & \multirow{2}{*}{1.9} & \multirow{2}{*}[0.9-1.92]{} \\
\hline & $\geq 35$ & 0.0 & 0.0 & 5 & 3.8 & & & \\
\hline \multicolumn{9}{|l|}{ Maternal weight (kg) } \\
\hline & $<60$ & 40 & 35.7 & 72 & 64.3 & \multirow{2}{*}{0.038} & \multirow{2}{*}{1.5} & \multirow{2}{*}[1.2-2.0]{} \\
\hline & $\geq 60$ & 20 & 25.6 & 58 & 44.6 & & & \\
\hline
\end{tabular}

Table 2. A woman who gave birth to an infant less than $2500 \mathrm{~g}$ as compared to woman who gave birth to a newborn of $2500 \mathrm{~g}$ or more as obstetric settings.

\begin{tabular}{|c|c|c|c|c|c|c|c|c|}
\hline \multirow{3}{*}{ Obstetric settings } & & \multicolumn{4}{|c|}{ Birth weight } & \multirow{3}{*}{$\mathrm{p}$-value } & \multirow{3}{*}{$\begin{array}{c}\text { OR } \\
\text { gross }\end{array}$} & \multirow{3}{*}{$\begin{array}{c}\text { IC } \\
(95 \%)\end{array}$} \\
\hline & & \multicolumn{2}{|c|}{$<2500 \mathrm{~g}$} & \multicolumn{2}{|c|}{$\geq 2500 \mathrm{~g}$} & & & \\
\hline & & $\mathrm{n}=60$ & $\%$ & $\mathrm{n}=130$ & $\%$ & & & \\
\hline \multicolumn{9}{|l|}{ Multiparous } \\
\hline & Yes & 16 & 21.6 & 58 & 78.4 & \multirow{2}{*}{0.018} & \multirow{2}{*}{2.5} & \multirow{2}{*}[1.2-4.9]{} \\
\hline & No & 44 & 37.9 & 72 & 62.1 & & & \\
\hline \multicolumn{9}{|l|}{ History of abortion } \\
\hline & Yes & 36 & 43.9 & 46 & 56.1 & \multirow{2}{*}{0.001} & \multirow{2}{*}{2.7} & \multirow{2}{*}[1.5-5.1]{} \\
\hline & No & 24 & 22.2 & 84 & 77.8 & & & \\
\hline \multicolumn{9}{|l|}{ Antenatal care } \\
\hline & Yes & 23 & 25.8 & 66 & 74.2 & \multirow{2}{*}{0.110} & \multirow{2}{*}{0.6} & \multirow{2}{*}[0.3-1.1]{} \\
\hline & No & 37 & 36.6 & 64 & 63.4 & & & \\
\hline \multicolumn{9}{|l|}{$\begin{array}{c}\text { History of } \\
\text { premature labor }\end{array}$} \\
\hline & Yes & 41 & 25.8 & 118 & 74.2 & \multirow{2}{*}{$<0.001$} & \multirow{2}{*}{4.6} & \multirow{2}{*}[2.0-10.2]{} \\
\hline & No & 19 & 25.6 & 12 & 74.4 & & & \\
\hline
\end{tabular}


Table 3. A woman who gave birth to an infant less than $2500 \mathrm{~g}$ as compared to a woman who gave birth to a newborn of $2500 \mathrm{~g}$ or more according to the disease diagnosed during pregnancy.

\begin{tabular}{|c|c|c|c|c|c|c|c|c|}
\hline \multirow{3}{*}{$\begin{array}{l}\text { Pathologies diagnosed } \\
\text { during pregnancy }\end{array}$} & & \multicolumn{4}{|c|}{ Birth weight } & \multirow{3}{*}{$\mathrm{p}$-value } & \multirow{3}{*}{$\begin{array}{c}\text { OR } \\
\text { gross }\end{array}$} & \multirow{3}{*}{ IC (95\%) } \\
\hline & & \multicolumn{2}{|c|}{$<2500 \mathrm{~g}$} & \multicolumn{2}{|c|}{$\geq 2500 \mathrm{~g}$} & & & \\
\hline & & $\mathrm{n}=60$ & $\%$ & $\mathrm{n}=130$ & $\%$ & & & \\
\hline \multicolumn{9}{|l|}{$\begin{array}{c}\text { Hypertension } \\
\text { during pregnancy }\end{array}$} \\
\hline & Yes & 37 & 56.1 & 29 & 43.9 & \multirow[t]{2}{*}{$<0.001$} & \multirow[t]{2}{*}{5.6} & \multirow[t]{2}{*}[2.9-10.9]{} \\
\hline & No & 23 & 18.5 & 101 & 81.5 & & & \\
\hline \multicolumn{9}{|l|}{ Malaria in Pregnancy } \\
\hline & Yes & 53 & 54.1 & 45 & 45.9 & \multirow{2}{*}{$<0.001$} & \multirow{2}{*}{14.3} & \multirow{2}{*}[6.0-34.0]{} \\
\hline & No & 7 & 7.6 & 85 & 92.4 & & & \\
\hline \multicolumn{9}{|l|}{$\begin{array}{c}\text { Anemia } \\
\text { during pregnancy }\end{array}$} \\
\hline & Yes & 45 & 71.4 & 18 & 28.6 & \multirow{2}{*}{$<0.001$} & \multirow{2}{*}{18.3} & \multirow{2}{*}[8.5-39.4]{} \\
\hline & No & 15 & 11.8 & 112 & 88.2 & & & \\
\hline
\end{tabular}

Table 4. A woman who gave birth to an infant less than $2500 \mathrm{~g}$ as compared to a woman who gave birth to a newborn of $2500 \mathrm{~g}$ or more according to the married mothers, Hypertension, Malaria and Anemia during pregnancy, History of abortion and premature labor.

\begin{tabular}{cccc}
\hline Variables & adjusted OR & IC 95\% & p-value \\
\hline Married mothers & 1.5 & {$[0.5-4.5]$} & 0.488 \\
Hypertension during pregnancy & 5.4 & {$[1.6-17.9]$} & 0.006 \\
Malaria during Pregnancy & 23.8 & {$[6.1-92.5]$} & $<0.001$ \\
Anemia during pregnancy & 11.8 & {$[3.7-38.2]$} & $<0.001$ \\
History of abortion & 4.4 & {$[1.4-13.9]$} & 0.012 \\
History of premature labor & 8.5 & {$[1.8-40.1]$} & 0.007 \\
\hline
\end{tabular}

After taking into account the interaction between the various factors, a mother who developed malaria during pregnancy has a risk 24 times greater of delivering a newborn less than $2500 \mathrm{~g}$. For a mother in whom anemia was diagnosed during pregnancy, the risk of delivering an infant of less than $2500 \mathrm{~g}$ is over 12 times higher and in the one that has developed a blood pressure, risk is increased 11 times. The premature birth and abortion history respectively multiplied by about 9 and 4, respectively, the risk of delivering an infant with low birth weight. The maternal weight below $60 \mathrm{~kg}$ rose to 4.46 times the risk of low birth weight.

\section{Discussion}

The risk factors for low birth weight demonstrated in this study tally with several studies conducted in Cameroon [8], Senegal [9], Congo Brazzaville [10], Tunisia 
[11] and Burkina Faso [12] [13]. These studies show a significant association between low birth weight and blood pressure, history of abortion, primiparity, low level of education, malaria, and low maternal weight. In contrast, Ndiaye et al. [14] did not find a significant relationship between the weight of the mother and the newborn. The link with high blood pressure which is also highlighted by Hastoy et al. [15] is explained by the fact that in the maternal blood pressure, there is a decrease in uteroplacental perfusion led to a reduction of intake of nutrients and oxygen to the fetus which results in an intrauterine growth retardation and ultimately a low birth weight. This decrease in uteroplacental perfusion is favored by the late detection of high blood pressure which is often discovered during a maternal and/or fetal complication. The link between low maternal weight and low birth weight can be explained one hand by genetic factors, because it is intuitive that a mother of a little weight might give birth to a newborn of small birth weight. On the other hand by maternal malnutrition, which not only reduces the weight of the mother but also the fetus. As for malaria, through its impact on maternal condition and placental infection, it causes an intrauterine growth restriction and thus the birth of a newborn of low birth weight. The link with anemia is explained by the fact that in maternal anemia nutritional intake and oxygen to the fetus is decreased and therefore the weight of the fetus as well. The occurrence of anemia is favored especially by intestinal parasites, malaria and malnutrition. The history of abortion and premature birth was significantly associated with low birth weight due to the fact that some risk factors of abortion and premature delivery are also risk factors for low birth weight [16]. Regarding parity, we found a decrease in low birth weight as parity increases. This same observation was made by Letaief [11] which speaks of a low weight birth rate higher in primiparous and Kangulu IB [17] who reports in his study in the Democratic Republic of Congo that the risk of low birth weight passes in primiparous 2.48 to 1.07 in multiparous and explains this by the competition for nutrients between the teenager growing and the developing fetus as well as the low efficiency of placental function at this age. The same situation was reported by Mabiala-Bibela JR who found that primiparity and high parity favor the occurrence of low birth weight [10]. Contrary to some published data [8] [10] [12] [17]. It was not found, as studies conducted in Senegal [18] and Morocco [19] a significant link between the number of antenatal care and low birth weight. A recent study in several developing countries has shown that inadequate prenatal care was among the least significant risk factors for the most important birth [20]. It should be noted that prenatal care is very bad in the Guinean population studied. Over $53 \%$ of women included in this study had no antenatal care and $38 \%$ had only 1 to 2 prenatal visits, so far from the minimum of 4 consultations requested by WHO. Among women who had four consultations recommended many have not taken regularly iron/folate tablets and sulfadoxine/pyrimethamine offered free to all pregnant women during antenatal care. The nets distributed during antenatal care to protect pregnant women against 
mosquito bites as malaria vectors are often used for other purposes (such as fishing nets or to protect gardens against certain insect pests). The lack of significant association between low birth weight and prenatal care in this study also indicates the poor quality of antenatal care in our context since during prenatal consultations, most risk factors reported by this study should be screened for, and a curative or preventive treatment initiated. The positive impact of intermittent preventive treatment with sulfadoxine/pyrimethamine during pregnancy is confirmed by the literature [21]. Marital status after consideration of third factor is no longer significantly associated with low birth weight. This finding is different from that reported by Traoré et al. [22]. The lack of connection with maternal age reported in this study is confirmed by the study in Senegal [9] but is contrary to the result of a study at Brazzaville [10] and one made in the Democratic Republic of Congo reported that mothers under 18 years are 7.62 times more likely to give birth a newborn with low birth weight and the risk becomes 2.04 in mothers over 35 years [17]. Letaiefin Tunis found that the rate of low birth weight is higher among mothers aged under 18 years [11]. Advanced maternal age has been shown in many countries as a risk factor for low birth weight [20] [23]. This was also confirmed by Mabiala Bibela JR-Brazzaville who found that maternal age is often linked to low birth weight with higher risk in adolescents and in women aged over 35 years [10]. The reason why this factor is not identified as a factor associated would be the fact that only $3.8 \%$ of women included in this study had an age beyond 35 years threshold shown in other studies.

\section{Limitations of the Study}

During this study, 49 files were removed for incomplete information. Furthermore, this did not take into account the nutritional status of the mother, the maternal size, the use of tobacco and alcohol by the mother who may have a relationship with the low weight at birth. It was not taken into account the prematurity, neither.

\section{Conclusions}

Significantly associated risk factors for low birth weight demonstrated in this study are: maternal weight below $60 \mathrm{~kg}$, malaria, anemia, high blood pressure during pregnancy and abortion history and premature delivery.

The decrease in the frequency of low birth weight will go through improving the quality of prenatal care with an emphasis on screening, prevention and treatment of malaria, anemia and high blood pressure during pregnancy, improving the nutritional status of women of childbearing age, prevention of abortion and premature birth.

\section{Conflicts of Interest}

The authors declare no conflicts of interest regarding the publication of this paper. 


\section{References}

[1] Wardlaw, T.M. (2004) Low Birthweight: Country, Regional and Global Estimates. World Health Organization, UNICEF, Eds. WHO, Geneva; UNICEF, New York.

[2] Flamingo, C. and Gascoin, G. (2013) Become Early and Taking Care of Neonatal Newborn Small for Gestational Age. Journal de Gynécologie-Obstétrique et biologie de la Reproduction, 42 985-995.

[3] Ministry of Planning of Guinea (2017) National Bureau of Statistics. Guinea Demographic and Health Survey and Multiple Indicator á (EDS-MICS) 2012 [FR280]-FR280.pdf [Internet]. https://dhsprogram.com/pubs/pdf/FR280/FR280.pdf

[4] Kabore, P., Potvliege, C., Sanou, H., Bawhere, P. and Dramaix, M. (2004) Weight Growth and Survival of Children LBW Term Infants in Rural Africa (Burkina Faso). Archives de Pédiatrie, 11, 807-814. https://doi.org/10.1016/j.arcped.2004.03.034

[5] Gascoin, G. and Flamingo, C. (2013) Long-Term Consequences of Children Born in a Context of Intrauterine Growth Restriction and/or Small for Gestational Age. Journal de Gynécologie Obstétrique et Biologie de la Reproduction, 42, 911-920. https://doi.org/10.1016/j.jgyn.2013.09.014

[6] Kabore, P., Donnen, P. and Dramaix Wilmet, M. (2009) Impact of Small Birth Weight at Term Morbidity and Infant Mortality in Rural Sahel. Journal de Pédiatrie et de Puériculture, 22, 121-127.

[7] Ministry of Public Health of Guinea. National Health Development Plan (NHDP) 2015-2024 [Internet].

http://www.nationalplanningcycles.org/sites/default/files/country_docs/Guinea/pla n_national_developpement_sanitaire_2015-2024_guinee_fin.pdf

[8] Chiabi, A., Miaffo, L., Mah, E., Nguefack, S., Mbuagbaw, L., Tsafack, J., et al. (2011) Risk Factors and Prognosis of Hospital Neonatal Low Birth Weight (Birth Weight Less Than 2500 Grams) in Gynecology and Obstetrics and Pediatric Hospital in Yaoundé, Cameroon. Journal de Pédiatrie et de Puériculture, 24, 125-132.

[9] Amine, M., Aboulfalah, A., Isaf, H. and Abassi, H. (2009) Risk Factors for Low Birth Weight: Case-Control Study. Revue d'Épidémiologie et de Santé Publique, 57, S8.

[10] Mabiala-Babela, J.R., Matingou, V.C. and Senga, P. (2007) Risk Factors for Low Birth Weight in Brazzaville, Congo. Journal de Gynécologie Obstétrique et Biologie de la Reproduction, 36, 795-798. https://doi.org/10.1016/j.jgyn.2007.06.007

[11] Letaief, M., Soltani, M.S., Salem, K.B. and Bchir. M.A. (2001) Epidemiology of underweight at Birth in the Tunisian Sahel. Public Health, 13, 359-366.

[12] Yugbaré, S.O., Kaboré, R., Koueta, F., Sawadogo, H., Dao, L., Nacro, B., et al. (2013) Risk Factors for Death of Newborns of Low Birth Weight in Ouagadougou (Burkina Faso). Journal de Pédiatrie et de Puériculture, 26, 204-209.

[13] Kabore, P., Donnen, P. and Dramaix-Wilmet, M. (2008) Obstetric Risk Factors of Low Birth Weight at Term Sahelian Rural Summary. Public Health, 19, 489-497.

[14] Ndiaye, O., Sulla, A., Cissé, C.T., Guèye, M., Ndabashinze, P., Ouattara, A., et al. (2005) Influence of Excess Maternal Weight on the Birth Weight of Newborns in Terms of Population in Senegal. Journal de Pédiatrie et de Puériculture, 18, 33-37.

[15] Hastoy, A., Lien tran, P., Lakestani, O., Barau, G., Gérardin, P. and Boukerrou, M. (2015) The Hyperemesis Gravidarum: What Consequences on Pregnancy? Journal de Gynécologie-Obstétrique et biologie de la Reproduction, 44, 154-163.

[16] Torchin, H. and Ancel, P.Y. (2016) Epidemiology and Risk Factors of Prematurity. Journal de Gynécologie Obstétrique et Biologie de la Reproduction, 45, 1213-1230. https://doi.org/10.1016/j.jgyn.2016.09.013 
[17] Kangulu, I.B., Umba, E.K., Nzaji, M.K. and Kayamba, P.K. (2014) Risk Factors for Low Birth Weight in Semi-Rural Kamina, Democratic Republic of Congo. Pan African Medical Journal, 17, 220.

[18] Ndiaye, O., et al. (2006) Risk Factors Associated with Low Birth Weight. About a Case-Control Study in the Maternity of the Regional Hospital in Thies (Senegal). The Journal of Pediatrics, 19, 153-158.

[19] Hassoun, S., Bassel, S., Nani Elbouri, H., Zine, K. and Maaroufi, A. (2015) Maternal Factors Associated with Low Birth Weight: Case-Control Study in a Moroccan Public Hospital. Maternal Factors Associated with Low Birth Weight. Case-Control Study in a Moroccan Public Hospital. Pan African Medical Journal, 20, 303.

[20] van den Boogaard, W., Zuniga, I., Manzi, M., Van den Bergh, R., Lefevre, A., Nanan N'zeth, K., et al. (2017) How Do Low-Birthweight Neonates Fare 2 Years after Discharge from a Low-Technology Neonatal Care Unit in a Rural District Hospital in Burundi? Too Much. Tropical Medicine \& International Health, 22, 423-430. https://doi.org/10.1111/tmi.12845

[21] Moleins, I., Agnamey, P., Badiane, M., Totet, A. and Brasseur, P. (2010) Malaria in Pregnancy: Impact of Intermittent Preventive Treatment with Sulfadoxine Pyrimethamine on Birth Weight Motherhood Oussouye (Casamance, Senegal). La Revue Sage-Femme, 9, 123-127. https://doi.org/10.1016/j.sagf.2010.04.003

[22] Traore, H., Meda, N., Nagot, N., Somé, E., Neboua, D., Kankasa, C., et al. (2013) Determinants of Low Birth Weight in Children Born to HIV Positive Mothers for HIV, Not Eligible for Antiretroviral Treatment in Africa. Revue d Epidémiologie et de Santé Publique, 61, 413-420. https://doi.org/10.1016/j.respe.2013.05.022

[23] Klemetti, R., Gissler, M., Sainio, S. and Hemminki, E. (2016) At What Age Does the Risk for Adverse Maternal and Infant Outcomes Increase? Nationwide Register-Based Study on First Births in Finland in 2005-2014. Acta Obstetricia et Gynecologica Scandinavica, 95, 1368-1375. https://doi.org/10.1111/aogs.13020 